\title{
CORRESPONDENCE
}

\section{No crisis in supply of peer reviewers}

At the journal Molecular Ecology, we find little evidence for the common belief that the peerreview system is overburdened by the rising tide of submissions.

We analysed the number of requests required in 2001-10 to obtain a review; compared the number of submissions in 2001-07 with the number of unique reviewer names in each year; and calculated the mean number of reviews per reviewer in 2001-07 (see go.nature.com/ 68mh16).

The idea that it is now harder to find reviewers turns out to be true (the mean number of reviewing requests issued per review increased from $1.38($ s.e. $=0.02)$ in 2001 to 2.03 (s.e. $=0.05$ ) in 2010). However, this seems to be due to changes in technology rather than to changes in reviewers' attitudes: the declining acceptance rate by invited reviewers strongly correlates with the 2008 transition from an e-mail-based editorial system to an automated one, perhaps because spam filters blocked e-mail invitations.

We also found that the reviewer pool expanded in proportion to the increased submission rate (which doubled between 2001 and 2007), yet there was no increase in the average number of reviews by individual reviewers.

The authors of the additional papers are the most likely source of the extra reviewers. Each Molecular Ecology submission has an average of 4.5 authors and decisions are based on an average of 2.7 reviews, so only 0.6 reviews per co-author are required to compensate for the review burden of each new article. These figures indicate that the reviewer pool still seems able to accommodate the increasing number of submissions.

Tim Vines, Loren Rieseberg Molecular Ecology, University of British Columbia, Canada.

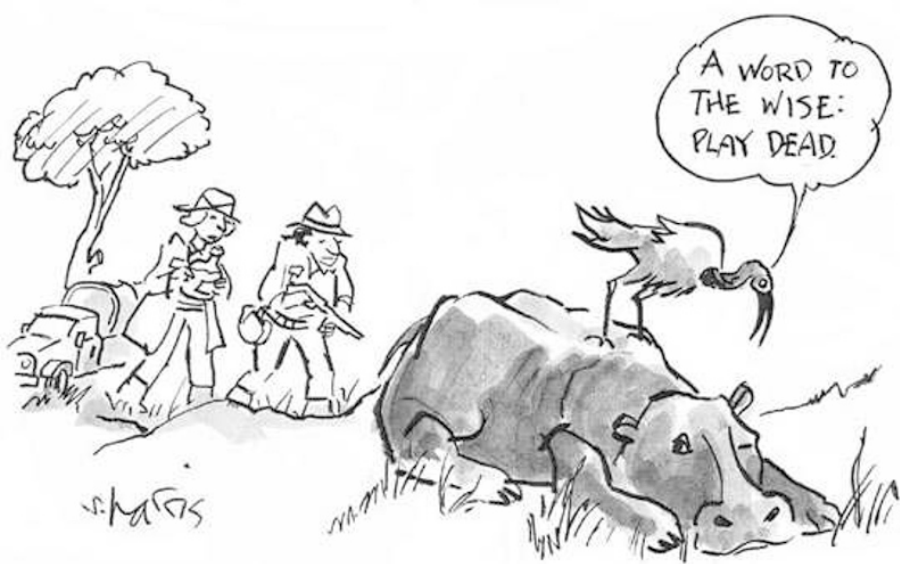

managing.editor@molecol.com Harry Smith University of Leicester, UK.

Competing financial interests declared: see http://dx.doi. org/10.1038/4681041a.

\section{Brazil's renewable energy success}

Brazil's advanced energy matrix is starting to pay off: $47.3 \%$ of its primary energy is now renewable. The world average is still around $13 \%$.

Last year, Brazil produced 244 million TOE (tonnes of oil equivalent), of which $42.6 \%$ came from oil and coal, and the rest from sugar cane (18.2\%), hydropower (15.2\%), biomass (13.9\%), natural gas (8.7\%) and uranium (1.4\%).

Ethanol accounted for $18.8 \%$ of fuel usage, and natural gas and biodiesel for 3.3\%. In just 2 years, Brazil has reached its target of $5 \%$ biodiesel additive in diesel. Ethanol is set to overtake petrol as fuel, thanks to flexible-fuel engines that use both at the same time. These account for $90 \%$ of small-car sales in the past 2 years.

The country is developing the technology for 'green' petrol and diesel production from sugar cane and agricultural waste, and from the castor-oil residue generated during biodiesel manufacture.

Brazil's government estimates that only about $2.5 \%$ of arable land will be needed to meet the ethanol demand forecast for 2017 (today this is 1.4\%). Burning of sugar-cane pulp (bagasse) is expected to supply $15 \%$ of Brazil's electricity by 2017 , comparable to that being generated by the Itaipu hydropower plant on the Brazil-Paraguay border.

Allan Kardec Duailibe National Agency of Petroleum, Natural Gas and Biofuels, Brazil.

allan@anp.gov.br

\section{Economic growth: a gross measure}

Gross domestic product (GDP) is as poor a measure of the economy as it is of welfare (Nature 468, 370-371; 2010).

Quantifying the concept of 'the economy' is contentious because of arbitrary decisions as to what to include, and because of a drift when indexing to constant prices. For example, should the jump in price from Walkman to iPod be classed as inflation or as a $10^{9}$ increase in storage productivity?

And whereas economic growth theory uses a production value that is net of depreciation, GDP is a gross measure. Thus GDP looks good even when things are falling apart. Being the fastest-growing economy in the 2000s was actually a sign of economic distress, not success, for the United Kingdom.

The economy, as a complex system, cannot logically be indexed by a single figure. In truth, GDP just reflects the perspective of the tax base, because that is how the figures are collected and presumably why the UK Treasury is keen to use it.

Force-feeding an economy's GDP index usually empties its environmental capital first, then its social capital and then whatever cash is left in the bank. David Fisk Imperial College London, UK. d.fisk@imperial.ac.uk

\section{Misreporting: hippo stories off-target}

Prevention is better than cure when it comes to the weight of ill-informed public opinion resulting from the misreporting of science by the media (Nature $468,7 ; 2010)$.

Take the story of a hippopotamus coming round unexpectedly in an African national park after incomplete delivery of an immobilizer drug cocktail by a faulty dart. The animal had to be shot after attacking the attending researchers.

News of the killing spread rapidly (see go.nature.com/ upkcu7), the story becoming more sensational with each rewriting (see go.nature.com/ rhhx7c). It prompted a public outcry and led some people to question why the research was being performed in the first place.

Not reported was that the new drug cocktail had until then been used with 100\% success on more than 20 hippos, and that previously trialled immobilization drugs had killed a quarter of the hippos tested. The real news is that this cocktail represents a breakthrough in the management and conservation of the species.

P. J. N. de Bruyn University of Pretoria, South Africa.

pjndebruyn@zoology.up.ac.za 